\title{
Malignant Fibrous Histiocytoma - An Unusual Transformation from Benign to Malignant
}

\author{
Ashima Bali', Mohit Pal Singh², Padmavathi ${ }^{3}$, Manisha Khorate ${ }^{4}$, Junaid Ahmed ${ }^{5}$ \\ ${ }^{1}$ Post-Graduate Student, Department Of Oral Medicine \& Radiology, Pacific Dental College \& Hospital, Udaipur, Rajasthan \\ ${ }^{2}$ Reader, Department of Oral Medicine \& Radiology, Pacific Dental College \& Hospital, Udaipur, Rajasthan \\ ${ }^{3}$ Professor, Department of Oral Medicine \& Radiology, Pacific Dental College \& Hospital, Udaipur, Rajasthan \\ ${ }^{4}$ Senior Lecturer, Department of Oral Medicine \& Radiology, Pacific Dental College \& Hospital, Udaipur, Rajasthan \\ ${ }^{5}$ Professor \& Head of the Department, Department Of Oral Medicine \& Radiology, Pacific Dental College \& Hospital, Udaipur, Rajasthan
}

\begin{abstract}
Background: Malignant Fibrous Histiocytoma (MFH) is one of the most common soft tissue sarcoma in adults and typically arises in the soft tissues of the extremities and retroperitoneum. The head and neck region are seldom involved accounting for $3-8.5 \%$ of the cases. In the superficial sites such as skin, MFH may behave in a benign fashion despite the high grade appearing and fast growing tumor cells, with a reported incidence of malignant transformation around $1 \%$.
\end{abstract}

Case Description: A 72 year old male patient reported to the Department of Oral Medicine \& Radiology with a chief complaint of recurrent pain and swelling over the upper lip and nose region which was surgically drained a month back. This was the third occurrence of the swelling over the past 13 years. In the past 2 episodes, he was surgically treated for Benign Fibrous Histiocytoma (BFH). Surgical procedure and histopathological report confirmed malignant transformation into MFH in the recent episode.

Conclusion and Clinical Implications: This publication aims to highlight the possibility of malignant transformation of benign fibrous histiocytoma and the importance of long term followup.

Keywords: Benign Fibrous Histiocytoma (BFH), Malignant Fibrous Histiocytoma (MFH), Malignant Histiocytoma, soft tissue sarcoma, Malignant Fibrous Xanthoma

\section{Introduction}

Soft tissue sarcomas of the head and neck are rare mesenchymal malignant neoplasms accounting for less than $10 \%$ of all soft tissue sarcomas and approximately $1 \%$ of all head and neck neoplasms. Nevertheless, they represent an important group of tumors and are associated with significant morbidity and mortality (Farhood et al., 1990; Chen et al., 2005; Mendenhall et al., 2005; Eeles et al., 1993; Huber et al., 2006). MFH is a primitive, often pleomorphic sarcoma consisting of was first introduced by Kauffman and Stout, (1961). Despite the frequency of diagnosis, MFH has remained an enigma as no true cell of origin has ever been identified (WHOCT, 2002). Additionally, MFH has been associated with hematopoietic diseases such as non-Hodgkin's lymphoma, Hodgkin's proportion of local recurrence rate of MFH after initial local excision ranges between $16 \%$ and $52 \%$, and is related to size, partly fibroblast like and partly histiocyte like cells. The term lymphoma, multiple myeloma and malignant histiocytosis. The

depth of invasion and microscopically positive surgical margins (Le Doussal et al., 1996; Pezzi et al., 1992).

We present a case of 72 year old male patient with a history of $\mathrm{BFH}$. It showed a changing histologic picture during progression of the disease and its transformation into malignant phenotype. The changing histological picture during progression of the disease and transformation of borderline-benign lesions to malignant phenotype has been described. Reported incidence of malignant transformation is around 1\% (O'Brien and Stout, 1964).

\section{Case history}

A 72 year old male patient with a history of BFH reported to the Department of Oral Medicine \& Radiology with a chief complaint of swelling and pain over the middle third region of the face since 1 month. Pain was severe, continuous, localized in nature, associated with swelling and had gradually increased in size over a period of 1 month. A history of trauma was elicited in the middle third of face initially around 18 years back (in year 1982) leading to the loss of vision of right eye and fracture of the nose. Subsequently, the soft tissue growth started over the upper lip and labial mucosa. Patient was operated for the same in the year 1996 and the histopathological report revealed spindle shaped cells arranged in storiform pattern and ovoid histiocytic cells. Cellular atypia was absent, with no evidence of necrosis or hemorrhage, suggestive of Fibrous Histiocytoma. The soft tissue growth recurred in the year 2001 and was surgically excised and the histopathological report was confirmatory for Benign Fibrous Histiocytoma with no cellular atypia.

Prior to his recent visit to our department, the patient visited a local dental practitioner for relief of pain. An incision and drainage of the swelling along with the extraction of tooth no. 22 was done, followed by a course of analgesics and antibiotics. There was no significant relief and the swelling persisted, but the pain had reduced.

The medical history revealed that the patient was diabetic (Type

*Corresponding author: DR. ASHIMA BALI, Post-Graduate Student, Department Of Oral Medicine \& Radiology, Pacific Dental College \& Hospital, Debari, Udaipur, Rajasthan, E-mail: ashimabali2@yahoo.co.in

Received March 10, 2010; Accepted April 06, 2010; Published April 06, 2010

Citation: Bali A, Singh MP, Padmavathi, Khorate M, Ahmed J (2010) Malignant Fibrous Histiocytoma - An Unusual Transformation from Benign to Malignant. J Cancer Sci Ther 2: 053-057. doi:10.4172/1948-5956.1000023

Copyright: ( 2010 Bali A, et al. This is an open-access article distributed under the terms of the Creative Commons Attribution License, which permits unrestricted use, distribution, and reproduction in any medium, provided the original author and source are credited.

J Cancer Sci Ther
Volume 2(2) : 053-057 (2010) - 053 
Citation: Bali A, Singh MP, Padmavathi, Khorate M, Ahmed J (2010) Malignant Fibrous Histiocytoma - An Unusual Transformation from Benign to Malignant. J Cancer Sci Ther 2: 053-057. doi:10.4172/1948-5956.1000023

II Diabetes Mellitus) since the last 10 years and was on oral medication which consisted of tab.Metformin 500mg 12 hourly. The patient had discontinued the medication since 6 months due to negligence.

Extra-oral examination (Figure 1) revealed facial asymmetry due to diffuse swelling over the upper lip with no change in the colour of the skin. The left nasolabial fold was obliterated and a fibrous surgical scar was seen involving the nose and cheek region. Nose was depressed and deviated towards the left side of the face with flattening and elevation of the left nare. Lips were incompetent (Figure 2). The swelling of the upper lip measured around $7 \times 9 \mathrm{~cm}$ and was firm and non-fluctuant. The lymph nodes were non palpable.

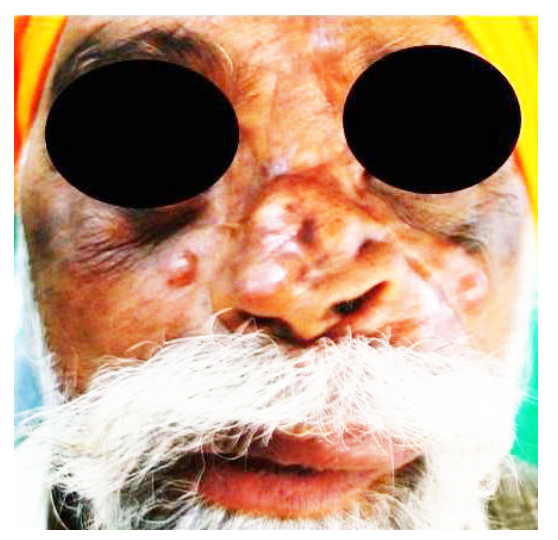

Figure 1

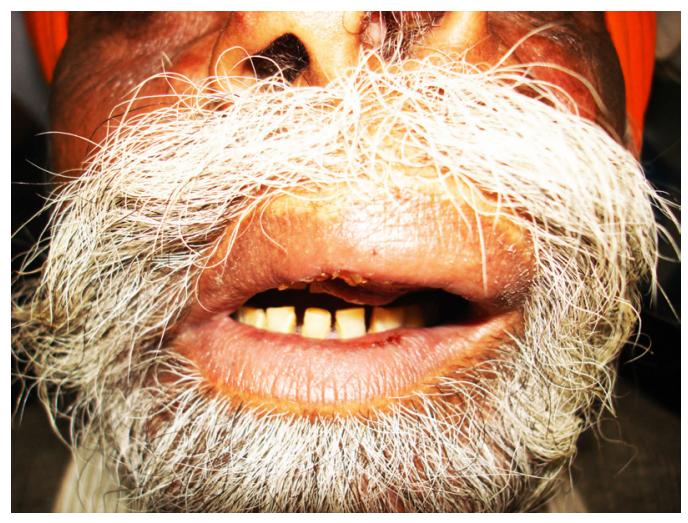

Figure 2

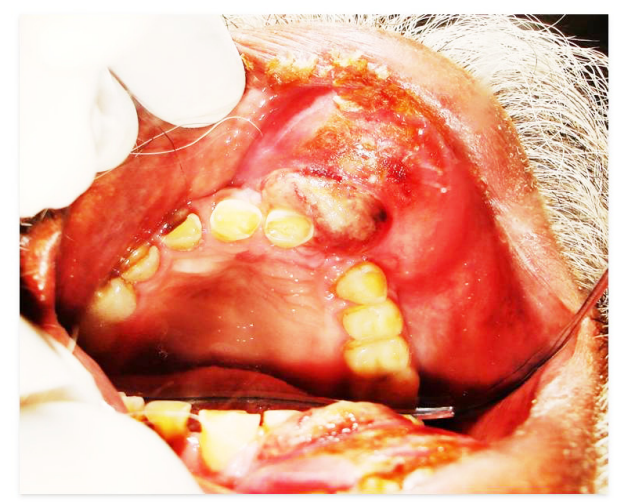

Figure 3

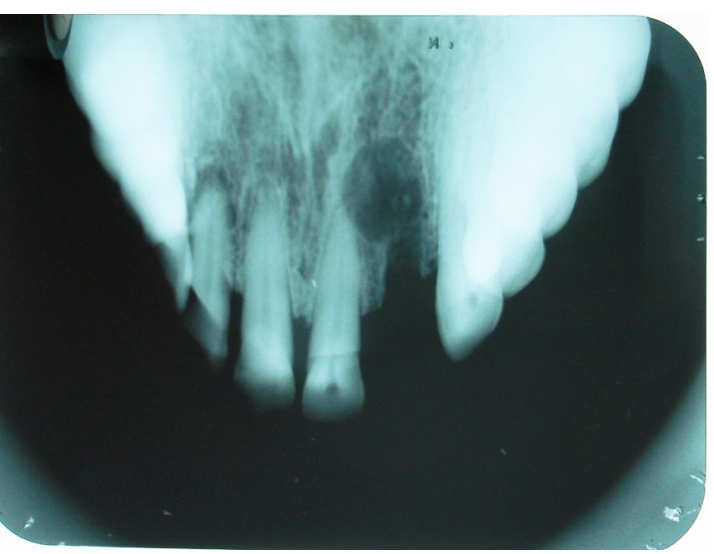

Figure 4

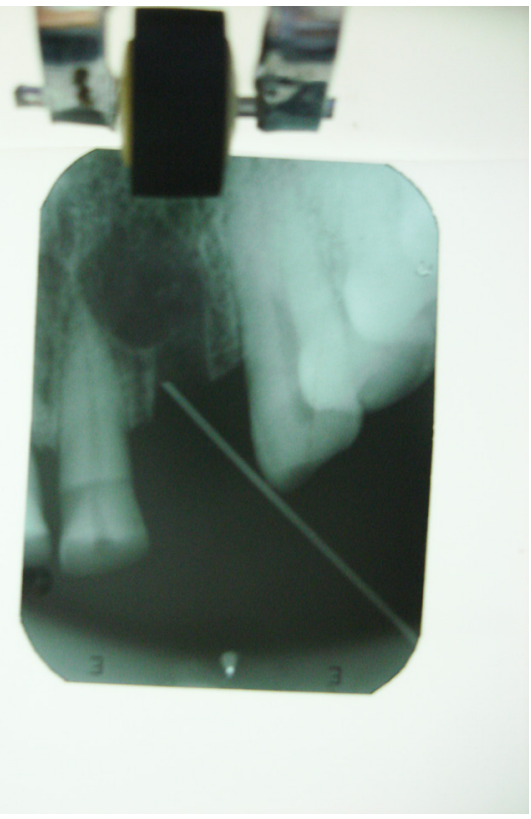

Figure 5

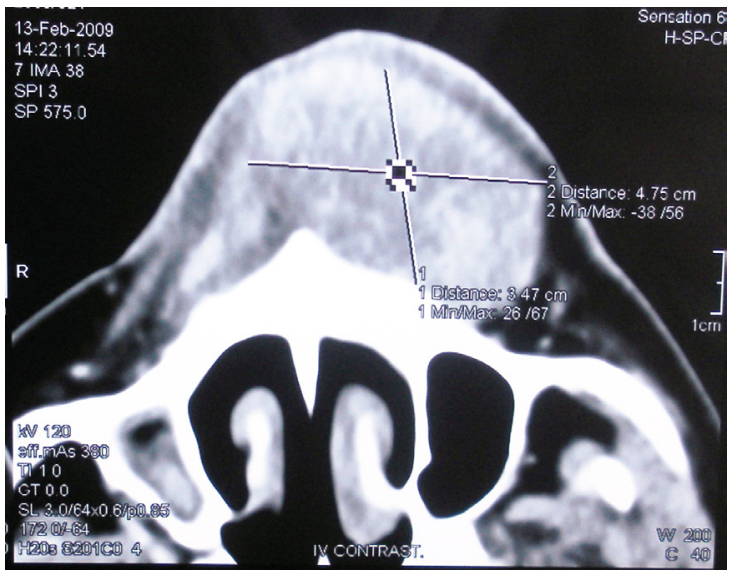

Figure 6

Intra-oral examination (Figure 3) revealed a well-defined, dome-shaped, reddish pink firm swelling in relation to the upper gingival and labial mucosa with no palatal extensions. Crustations were present over its superior surface which extended from tooth no. 11 to 23 region with an intra-oral draining sinus in the region of recently extracted 22 . 


\section{Journal of Cancer Science \& Therapy - Open Access \\ JCST/Vol.2 Issue 2}

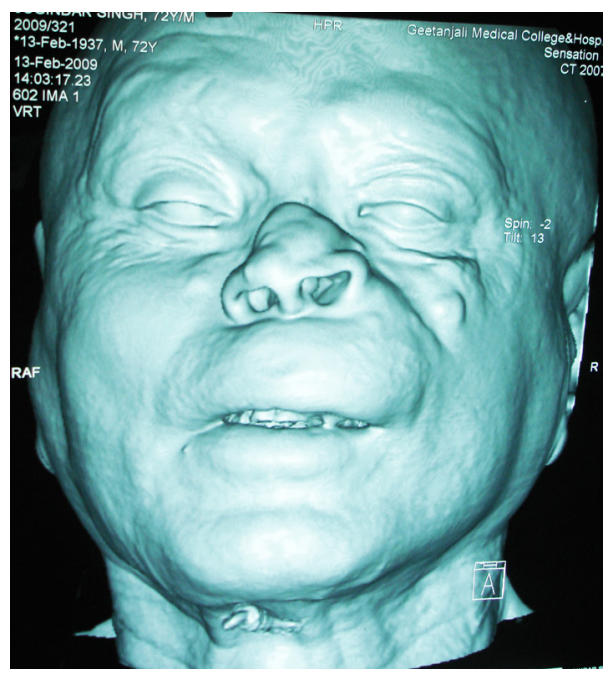

Figure 7

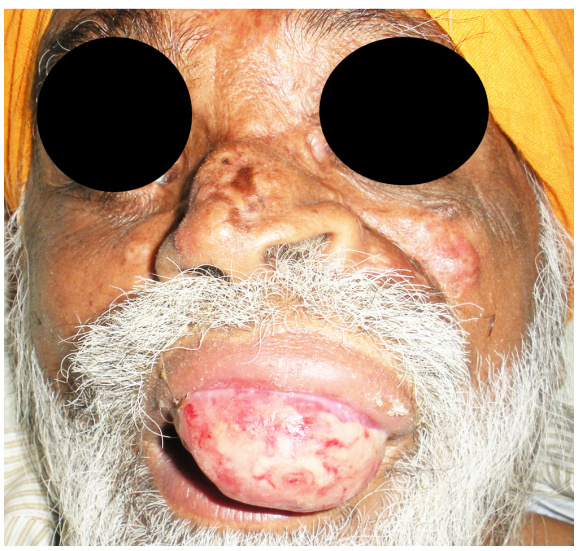

Figure 8

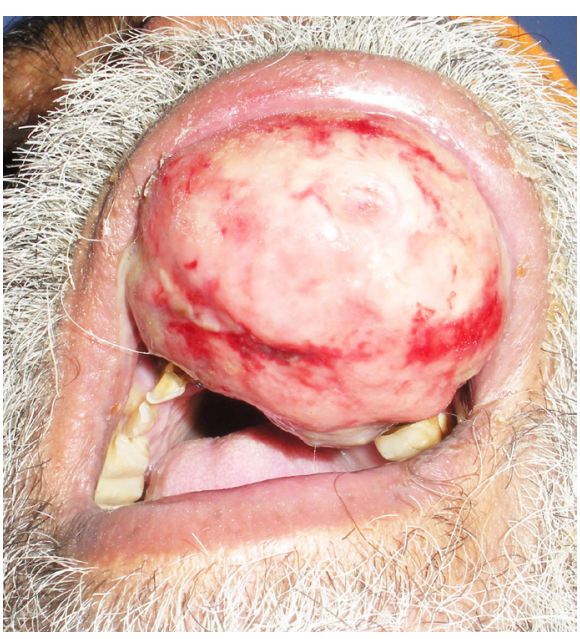

Figure 9

The blood picture was normal except for the raised blood glucose levels.

Radiographic examination (Figure 4) revealed a well defined radiolucency in relation to the socket of 22 extending upto periapical region of 11 . On tracing the sinus tract (Figure 5), it was found to be in relation with socket of 22, suggesting the presence of an infected residual cyst in relation to the socket of 22.

Computerized Tomography $(\mathrm{CT})$ was advised to note the extent and invasion into the underlying bone. CT (Figure 6, Figure 7) revealed a soft tissue density mass over the left side of the nose/ face extending upto the infraorbital margin and crossing midline.

History and CT findings were suggestive of recurrent BFH.

Patient delayed reporting back for biopsy and after 20 days the soft tissue swelling had substantially increased in size

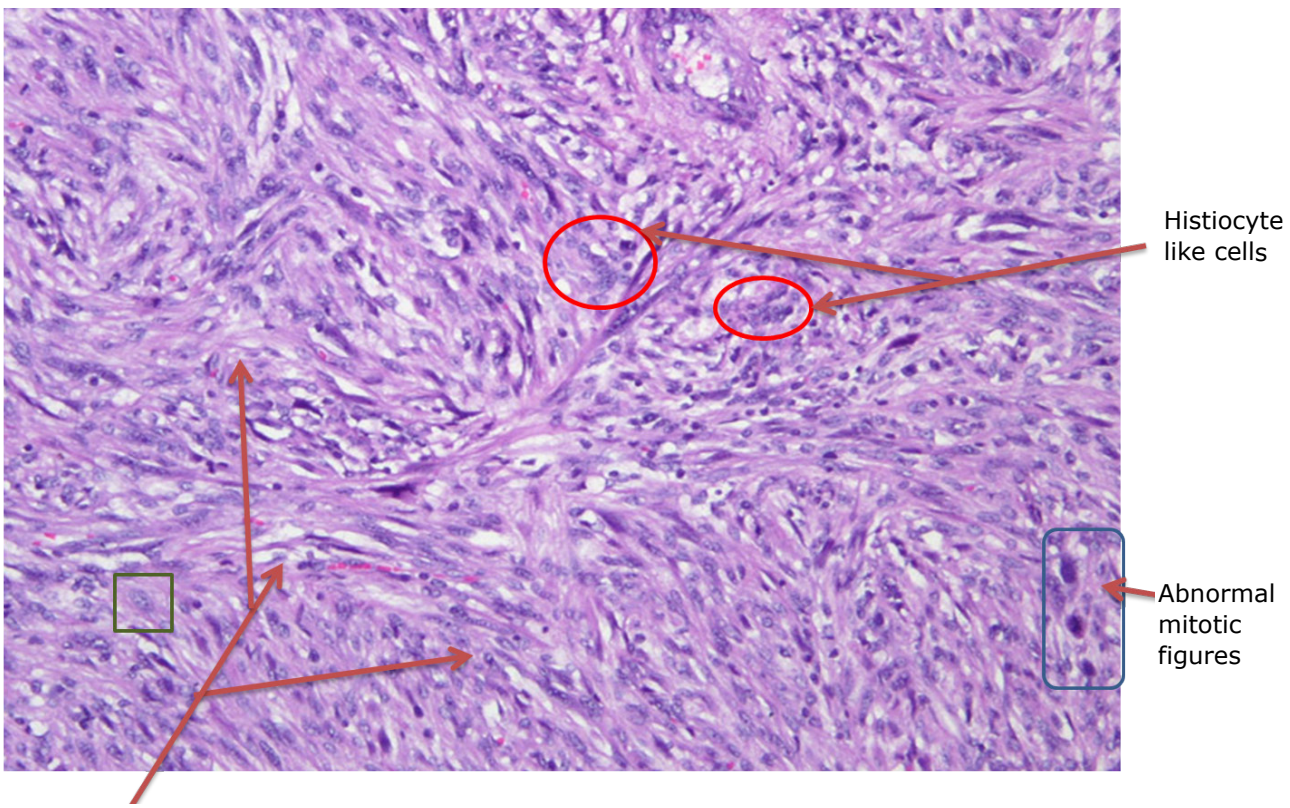

\begin{abstract}
Characteristic tangled (storiform) arrangement of the fibroblasts like spindle cells
\end{abstract}

Green square - Giant calls

Figure 10 
indicating a possibility of malignant transformation (Figure 8, Figure 9).

An incisional biopsy revealed dense cellularity forming the storiform or the criss cross pattern, along with spindle shaped cells with plump or vesicular nuclei admixed with inflammatory cells. Abnormal mitotic figures, necrosis and extensive cellular atypia were also seen (Figure 10). These findings were suggestive of Malignant Fibrous Histiocytoma.

A wide surgical excision of the soft tissue mass with a segment of the maxillary bone extending from tooth no. 12 to 23 was done followed by stent placement. The histopathological evaluation of the excised specimen reconfirmed the diagnosis of Malignant Fibrous Histiocytoma.

\section{Discussion}

MFH was first introduced by Kauffman and Stout, (1961), and they described it as a tumor rich in histiocytes, with a storiform growth pattern. O'Brien and Stout, (1964) named it as Malignant Fibrous Xanthoma. It was widely accepted as a clinicopathological entity after the description of cases by Kempson and Kyriakos, (1972). By 1977, MFH was considered the most common soft tissue sarcoma occurring in the late adult life especially in the extremities, lower extremities, followed by retroperitoneum and deep fascia or the skeletal muscle. MFH has been reported to occur in the lung, kidney, bladder, scrotum, nasal cavity, oral cavity, nasopharynx, and soft tissues of head and neck.

MFH has remained an enigma since no true cell of origin has ever been identified. In 2002, the World Health Organization (WHO) declassified MFH as a formal diagnostic entity and renamed it as an undifferentiated pleomorphic sarcoma not otherwise specified, NOS (Fletcher, 1992). This new terminology has been supported by a compelling body of evidence over the last decade to suggest that MFH represents a final common pathway in tumors that undergo progression towards undifferentiation (WHOCT, 2002; Dehner, 1988; Akerman, 1997; Hollowood K, Fletcher, 1995).

MFH can occur at any age, although the disease is extremely rare during infancy and early childhood (Pezzi et al., 1992; Weiss and Enzinger, 1978). The tumor has a peak incidence in the seventh decade with a male: female ratio of 2:1 (Pezzi et al., 1992; Weiss and Enzinger, 1978; Barnes, 1985; Blitzer et al., 1981). The etiology for MFH is debatable as no true cell of origin has ever been identified. Ionizing radiations (which are used for treatment of head and neck cancers), oncogenes and protooncogenes have been identified in the transformation of soft tissue cells to malignant fibrous histiocytoma. Trauma does not cause MFH but often the incidence draws attention to the extremity. The case here is also associated with a similar history of trauma to middle-third of face in the year 1982 after which the soft tissue swelling started. The mass does not usually cause any pain unless it is compressing a nearby nerve. Symptoms such as weight loss and fatigue are not typical but can present in patients with advanced disease. The most common sites of occurrence in the head and neck region are the sinonasal tract, soft tissues of the neck, craniofacial bones and salivary glands (Hollowood and Fletcher, 1995).
The changing histological picture during progression of the disease and transformation of borderline-benign lesions to malignant phenotype has been described. Reported incidence of malignant transformation is around 1\% (O'Brien and Stout, 1964). The malignant transformation of the BFH in some cases has been reported in the same area after it had been surgically treated ${ }^{19}$. In one such case reported, MFH developed in close proximity to the area of the mandible excised (Izumi et al., 2007). According to the cases reported, MFH transformed not only from BFH but from other tumors also (Mori et al., 2000; Ortiz-Cruz et al., 1995).

Enzinger and Weiss (Enzinger and Weiss, 1995) defined 5 subtypes of MFH as follows:

Storiform-pleomorphic, Myxoid, Giant cell, Inflammatory, Angiomatoid types.

The storiform-pleomorphic pattern, as in our case, is the most common subtype (Kearney et al., 1998) accounting for $70 \%$ of cases. The most favorable prognosis is associated with the angiomatoid and myxoid types of $\mathrm{MFH}$, whereas a poorer prognosis is reported with the giant cell variant. The Giant cell variant represents a highly aggressive lesion in regard to local growth, local recurrence, and distant metastasis. The storiformpleomorphic and inflammatory MFHs fall between these two extremes. The exact histiogenesis of the tumor remains unclear and controversial (WHOCT, 2002). It was initially proposed that the histiocytes that characterize the disease were acting as facultative fibroblasts, and this explained the apparent bimodal cell population found histologically. The neoplastic histiocytes possess ultra structural attributes such as collagen production of fibroblasts (Merkow et al., 1971). According to another theory (Roholl et al., 1985), ultra structural and tissue culture experiments showed small numbers of undifferentiated mesenchymal cells, suggesting that the histiocytic and fibrocytic cell lines are derived from these progenitor cells (Weiss and Enzinger, 1978; Fu et al., 1975; Shirastura et al., 1985). This could explain the diverse presentations of these tumors and the overlap that occurs among the various histologic types.

Development of metastasis depends on the tumor's subtype. Metastasis occurs most frequently to the lung (90\%), bone (8\%) and liver $(1 \%)$. In the extremities, it presents as a painless enlarging soft tissue mass. It can spread anywhere in the soft tissues, but can also occur at previous sites of radiation treatment.

Treatment for MFH mainly consists of surgery, radiation and chemotherapy. Chemotherapy has been used in patients with a predictably high risk of pulmonary metastasis (Le Doussal et al., 1996; Pezzi et al., 1992; Otsuka et al., 2001). Wide resection of the tumors located in the head and neck region with adequate margins of normal surrounding tissues is required for a favorable prognosis (Le Doussal et al., 1996; Pezzi et al., 1992; Blitzer et al., 1981). Since regional lymph nodes are involved in $10 \%$ to $18 \%$ of cases (Pezzi et al., 1992; Fletcher, 1992; Weiss and Enzinger, 1978; Barnes, 1985; Kearney et al., 1980), consideration should be given to elective neck dissection for patients with advanced-stage disease or evidence of aggressive histopathological features (Hollowood and Fletcher, 1995; Barnes, 1985). Since the lymph nodes were not involved in our case, only surgical resection of the tumor along with maxillary 


\section{Journal of Cancer Science \& Therapy - Open Access JCST/Vol.2 Issue 2}

alveolectomy and margins of the surrounding tissues was done. The decision of whether to subject a patient to radiation therapy depends on the size, site, histologic grade, and the width of surgical markings (Le Doussal et al., 1996; Pezzi et al., 1992; Kearney et al., 1980). In our case looking at the patient's age, socio-economic status and the unwillingness for radio/ chemotherapy, only wide resection was planned. The follow-up of the patient after the surgical excision has shown no recurrence of the soft tissue sarcoma till date.

\section{Conclusion}

The cellular features of the fibrohistiocytic tumors sometime make it difficult to predict the biological behavior of the soft tissue lesion. In the present case, the patient had initially presented with a benign histopathological appearance of the primary lesion which later due to its recurrent nature, presented a malignant histopathological picture. Hence a long term, closely monitored post-operative follow up of the benign fibrohistiocytic tumors, is mandatory, especially in recurrences, for the early detection of any possible malignant transformation.

\section{References}

1. Akerman M (1997) Malignant fibrous histiocytoma—the commonest soft tissue sarcoma or a nonexistent entity? Acta Orthop Scand 273: 41-6. » CrossRef » PubMed » Google Scholar

2. Barnes L (1985) Tumors and tumor like lesions of the soft tissues. In: L. Barnes, Editor. Surgical Pathology of the Head and Neck 1: 725-880. »CrossRef » PubMed » Google Scholar

3. Blitzer A, Lawson W, Zak FG, Biller HF, Som ML (1981) Clinical-pathological determinants in prognosis of fibrous histiocytomas of the head and neck. Laryngoscope 91: 2053-2070. » CrossRef » PubMed » Google Scholar

4. Chen SA, Morris CG, Amdur RJ, Werning JW, Villaret DB, et al. (2005) Adult head and neck soft tissue sarcomas. Am J Clin Oncol 28: 259-263. » CrossRef » PubMed » Google Scholar

5. Dehner LP (1988) Malignant fibrous histiocytoma. Nonspecific morphologic pattern, specific pathologic entity, or both? Arch Pathol Lab Med 112: 236-7. »CrossRef » PubMed » Google Scholar

6. Eeles RA, Fisher C, A'Hern RP, Robinson M, Rhys-Evans P, et al. (1993) Head and neck sarcomas: prognostic factors and implications for treatment. $\mathrm{Br} \mathrm{J}$ Cancer 68: 201-207. » CrossRef » PubMed » Google Scholar

7. Enzinger FM, Weiss SW (1995) Soft tissue tumors. 3rd ed. Mosby: St.louis. $»$ CrossRef » PubMed » Google Scholar

8. Farhood AI, Hajdu SI, Shiu MH, Strong EW (1990) Soft tissue sarcomas of the head and neck in adults. Am J Surg 160: 365-369. » CrossRef » PubMed » Google Scholar

9. Fletcher CD (1992) Pleomorphic malignant fibrous histiocytoma: fact or fiction? A critical reappraisal based on 159 tumors diagnosed as pleomorphic sarcoma. Am J Surg Pathol 16: 213-28. » CrossRef » PubMed » Google Scholar

10. Fu YS, Gabbiani G, Kaye GI, Lattes R (1975) Malignant soft tissue tumors of probable histiocytic origin (malignant fibrous histiocytomas): General considerations and electron microscopic and tissue culture studies. Cancer 35: 176-198. » CrossRef » PubMed » Google Scholar

11. Hollowood K, Fletcher CD (1995) Malignant fibrous histiocytoma: morphologic pattern or pathologic entity? Semin Diagn Pathol 12: 210-20. »CrossRef » PubMed » Google Scholar
12. Huber GF, Matthews TW, Dort JC (2006) Soft-tissue sarcomas of the head and neck: a retrospective analysis of the Alberta experience 1974 to 1999. Laryngoscope 116: 780-785. » CrossRef » PubMed » Google Scholar

13. Izumi K, Cheng J, Maeda T, Saku T (2007) Malignant fibrous histiocytoma arising in the abutting soft tissue after resection of the benign fibrous histiocytoma of the mandible. Oral Oncology Extra 20: 24-28. » CrossRef » PubMed » Google Scholar

14. Kauffman SL, Stout AP (1961) Histiocytic tumors (fibrous xanthoma and histiocytoma) in children. Cancer 14: 469-82. » CrossRef » PubMed » Google Scholar

15. Kearney MM, Soule EH, Ivins JC (1980) Malignant fibrous histiocytoma. A retrospective study of 167 cases. Cancer 45: 167-178. » CrossRef » PubMed » Google Scholar

16. Kempson RL, Kyriakos M (1972) Fibroxanthosarcoma of the soft tissues. A type of malignant fibrous histiocytoma. Cancer 29: 961-976. »CrossRef » PubMed » Google Scholar

17. Le Doussal V, Coindre JM, Leroux A, Hacene K, Terrier P, et al. (1996) Prognostic factors for patients with localizec primary malignant fibrous histiocytoma. A multicenter study of 216 patients with multivariate anaylsis. Cancer 77: 1823-1830. » CrossRef » PubMed » Google Scholar

18. Merkow LP, Frich JC Jr, Slifkin M, Kyreages CG, Pardo M(1971) Ultrastructure of a fibroxanthosarcoma (malignant fibroxanthoma). Cancer 28: 372-383. » CrossRef » PubMed » Google Scholar

19. Mendenhall WM, Mendenhall CM, Werning JW, Riggs CE, Mendenhall NP (2005) Adult head and neck soft tissue sarcomas. Head \& Neck 27: 916-922. »CrossRef » PubMed » Google Scholar

20. Mori Y, Tsuchiya H, Karita M, Nonomura A, Nojima T, et al. (2000) Malignant transformation of giant cell tumor 25 years after initial treatment. Clin Orthop Relat Res 381: 185-191. » CrossRef » PubMed » Google Scholar

21. O’Brien JE, Stout AP (1964) Malignant Fibrous Xanthomas. Cancer 17: 14451455. $»$ CrossRef $\gg$ PubMed $»$ Google Scholar

22. Ortiz-Cruz EJ, Quinn RH, Fanburg JC, Rosenberg AE, Mankin HJ (1995) Late development of Malignant fibrous histiocytoma at the site of Giant Cell. Clin Orthop Relat Res 318: 199-204. » CrossRef » PubMed » Google Scholar

23. Otsuka K, Hamakawa H, Sumida T, Tanioka H (2001) Treatment of mandibular malignant fibrous histiocytoma during pregnancy. J Oral Maxillofac Surg 59: 220-224. CrossRef » PubMed » Google Scholar

24. Pezzi CM, Rawlings MS Jr, Esgro JJ, Pollock RE, Romsdahl MM (1992) Prognostic factors in 227 patients with malignant fibrous histiocytoma. Cancer 69: 2098-103. » CrossRef » PubMed » Google Scholar

25. Roholl PJM, Kleijne J, Van Basten CDH, van der Putte SCJ, van Unnik JAM, et al. (1985) A study to analyze the origin of tumor cells in malignant fibrous histiocytomas. A multi parametric characterization. Cancer 56: 2809-2815. » CrossRef » PubMed » Google Scholar

26. Seper L, Schwab R, Kiattavorncharoen S, Büchter A, Bánkfalvi A (2007) Malignant fibrous histiocytoma of the face: report of a case. Head Face Med 3: 36. » CrossRef » PubMed » Google Scholar

27. Shirastura K, Sugiyami M, Miyazaki T (1985) Establishment and characterization of neoplastic cells from a malignant fibrous histiocytoma. A possible stem cell line. Cancer 55: 2521-2532. » CrossRef » PubMed » Google Scholar

28. Weiss SW, Enzinger FM (1978) Malignant fibrous histiocytoma. An analysis of 200 cases. Cancer 41: 2250-2266. » CrossRef » PubMed » Google Scholar

29. World Health Organization Classification of Tumors (2002) Pathology and Genetics of Tumors of Soft Tissue and Bone. Edited by Fletcher CDM, U. K., Mertens F., Lyon, France, IARC. » CrossRef » PubMed » Google Scholar 